Jurnal Matematika UNAND

Vol. VII No. 3 Hal. $47-53$

ISSN : 2303-291X

(C)Jurusan Matematika FMIPA UNAND

\title{
REACHABILITY POSITIF DARI SISTEM DISKRIT LINIER POSITIF
}

\author{
FERNANDO SIHOTANG, RADHIATUL HUSNA \\ Program Studi S1 Matematika, \\ Fakultas Matematika dan Ilmu Pengetahuan Alam, Universitas Andalas, \\ Kampus UNAND Limau Manis Padang, Indonesia, \\ email: :fsihotang012@gmail.com
}

\begin{abstract}
Abstrak. Dalam artikel ini dikaji uji reachability dari sistem diskrit linier positif. Beberapa konsep aljabar linier digunakan dalam kajian ini. Beberapa contoh disajikan untuk mengilustrasikan pengujian reachability.

Kata Kunci: Sistem linier positif, monomial, bebas linier, reachability

$\begin{array}{lll}\text { Diterima } & : & \text { 6 Juli } 2018 \\ \text { Direvisi } & : & 15 \text { September } 2018 \\ \text { Dipublikasikan } & : & 21 \text { Desember 2018 }\end{array}$
\end{abstract}

\section{Pendahuluan}

Diberikan suatu sistem linier sebagai berikut.

$$
\mathbf{x}(i+1)=A \mathbf{x}(i)+B \mathbf{u}(i), \mathbf{x}(0)=\mathbf{x}_{0},
$$

dimana $A \in \mathbb{R}^{n \times n}$ matriks keadaan, $B \in \mathbb{R}^{n \times m}$ matriks input, $\mathbf{x}(i) \in \mathbb{R}^{n}$ adalah vektor keadaan, $\mathbf{u}(i) \in \mathbb{R}^{m}$ adalah vektor input, dan $i \in \mathbb{Z}_{+}$. Dalam hal ini, $\mathbb{R}^{n \times n}$ menyatakan himpunan matriks-matriks riil berukuran $n \times n, \mathbb{R}^{n}$ menyatakan himpunan vektor-vektor riil yang terdiri dari $n$ baris, dan $\mathbb{Z}_{+}$menyatakan himpunan bilangan bulat nonnegatif. Solusi untuk sistem (1.1) diberikan sebagai berikut.

$$
\mathbf{x}(i)=A^{i} \mathbf{x}(0)+\sum_{k=0}^{i-1} A^{i-k-1} B \mathbf{u}(k) .
$$

Dalam sebagian aplikasi, solusi yang diperoleh terkadang adalah solusi yang nonnegatif sehingga muncul kajian terhadap sistem linier diskrit positif. Sistem (1.1) dikatakan positif jika $\mathbf{x}(i) \in \mathbb{R}_{+}^{n}$ untuk setiap $\mathbf{x}_{0} \in \mathbb{R}_{+}^{n}$ dan barisan $\mathbf{u}(i) \in \mathbb{R}_{+}^{m}$, $i \in \mathbb{Z}_{+}[4]$.

\section{Pembahasan}

Berikut akan disajikan beberapa Definisi dan Teorema yang akan digunakan untuk mendapatkan hasil utama

Definisi 2.1. [5] Suatu matriks $A \in \mathbb{R}_{+}^{n \times n}$ dikatakan matriks monomial jika dalam setiap baris dan kolom dari A terdapat tepat satu entri yang tak nol dan entri-entri lainnya adalah nol. 
Definisi 2.2. [7] Misalkan $e_{i}, i=1, \cdots, n$ adalah kolom ke $i$ dari matriks identitas $I_{n}$. Suatu kolom ae $e_{i}$ untuk $a>0$ disebut kolom monomial (entri kolom tersebut memiliki tepat satu entri positif, selainnya nol)

Jika $S=\mathbf{v}_{1}, \mathbf{v}_{2}, \cdots, \mathbf{v}_{r}$ adalah himpunan tak kosong vektor-vektor maka persamaan vektor

$$
k_{1} \mathbf{v}_{1}+k_{2} \mathbf{v}_{2}, \cdots+k_{r} \mathbf{v}_{r}=\mathbf{0}
$$

memiliki paling tidak satu solusi, yaitu

$$
k_{1}=0, k_{2}=0, \cdots, k_{r}=0
$$

Jika ini satu-satunya solusi maka $S$ disebut sebagai himpunan bebas linier (linearly independent). Jika terdapat solusi-solusi lain maka $S$ disebut sebagai himpunan bergantung linier (linearly dependent) [1].

Definisi 2.3. [5] Suatu keadaan $\mathbf{x}_{f} \in \mathbb{R}^{n}$ dikatakan reachable dalam $k$ langkah jika ada suatu barisan input $\mathbf{u}(i) \in \mathbb{R}^{m}, i=0,1, \cdots, k-1$ yang membawa keadaan awal $\mathbf{x}(0)=\mathbf{0}$ kepada keadaan $\mathbf{x}_{f}$.

Definisi 2.4. [5] Jika setiap keadaan $\mathbf{x}_{f} \in \mathbb{R}^{n}$ adalah reachable dalam $k$ langkah maka sistem (1.1) disebut reachable dalam $k$ langkah.

Berdasarkan Persamaan (1.2) untuk $\mathbf{x}(0)=\mathbf{0}$, diperoleh

$$
\mathbf{x}(k)=W \overline{\mathbf{u}}(k),
$$

dimana

$$
W=\left[B, A B, \cdots, A^{n-1} B\right] \quad \text { dan } \quad \overline{\mathbf{u}}(k)=\left(\begin{array}{c}
\mathbf{u}(k-1) \\
\mathbf{u}(k-2) \\
\vdots \\
\mathbf{u}(0)
\end{array}\right)
$$

Berdasarkan Persamaan (2.2) terlihat bahwa jika rank $W=n$ maka

$$
\overline{\mathbf{u}}(k)=W^{T}\left(W W^{T}\right)^{-1} \mathbf{x}_{f} .
$$

Teorema 2.5. [4] Sistem (1.1) adalah reachable jika dan hanya jika

$$
W=\left[B, A B, \cdots, A^{n-1} B\right]
$$

$\operatorname{rank}(W)=n$

Definisi 2.6. [5] Sistem (1.1) dikatakan positif jika $\mathbf{x}(i) \in \mathbb{R}_{+}^{n}$ untuk setiap $\mathbf{x}_{0} \in \mathbb{R}_{+}^{n}$ dan barisan $\mathbf{u}(i) \in \mathbb{R}_{+}^{m}, i \in \mathbb{Z}_{+}$.

Teorema 2.7. [6] Sistem (1.1) adalah positif jika dan hanya jika :

$$
A \in \mathbb{R}_{+}^{n \times n}, B \in \mathbb{R}_{+}^{n \times m}
$$

Bukti. $(\Rightarrow)$ Misalkan sistem (1.1) adalah positif. Akan ditunjukkan bahwa :

$$
A \in \mathbb{R}_{+}^{n \times n}, B \in \mathbb{R}_{+}^{n \times m} .
$$


Misalkan $\mathbf{u}(i)=\mathbf{0}$ untuk $i \in \mathbb{Z}_{+}$, maka untuk $i=1$ persamaan (1.2) menjadi

$$
\mathbf{x}(1)=A \mathbf{x}(0) \in \mathbb{R}_{+}^{n} .
$$

Keadaan awal $\mathbf{x}(0) \in \mathbb{R}_{+}^{n}$ yang diambil adalah sebarang, mestilah matriks $A \in$ $\mathbb{R}_{+}^{n \times n}$. Selanjutnya, misalkan $\mathbf{x}(0)=\mathbf{0}$, sedemikian sehingga untuk $i=1$ persamaan (1.2) dapat ditulis menjadi

$$
\mathbf{x}(1)=B \mathbf{u}(0) \in \mathbb{R}_{+}^{n}
$$

Diketahui bahwa $\mathbf{u}(0) \in \mathbb{R}_{+}^{r}$, maka mestilah matriks $\mathrm{B} \in \mathbb{R}_{+}^{n \times m}$. Jadi diperoleh

$$
A \in \mathbb{R}_{+}^{n \times n}, B \in \mathbb{R}_{+}^{n \times m}
$$

$(\Leftarrow)$ Misalkan

$$
A \in \mathbb{R}_{+}^{n \times n}, B \in \mathbb{R}_{+}^{n \times m}
$$

Berdasarkan Persamaan (1.2) jelas terlihat bahwa sistem positif.

Definisi 2.8. [6] Suatu keadaan $\mathbf{x}_{f} \in \mathbb{R}_{+}^{n}$ dikatakan reachable positif dalam $k$ langkah jika ada suatu barisan input $\mathbf{u}(i) \in \mathbb{R}_{+}^{m}, i=0,1, \cdots, k-1$ yang membawa keadaan awal $\mathbf{x}(0)=\mathbf{0}$ kepada keadaan $\mathbf{x}_{f}$.

Definisi 2.9. [6] Jika setiap keadaan $\mathbf{x}_{f} \in \mathbb{R}_{+}^{n}$ adalah reachable positif dalam $k$ langkah maka sistem (1.1) disebut reachable postif dalam k langkah.

Teorema 2.10. [6] Sistem positif (1.1) adalah reachable postif jika dan hanya jika matriks reachability $W$ dimana

$$
W=\left[\begin{array}{llll}
B & A B & \cdots & A^{n-1} B
\end{array}\right]
$$

memuat $n$ kolom monomial bebas linier.

Bukti. $(\Leftarrow)$ Misalkan matriks reachability $W$ memuat $n$ kolom monomial bebas linier. Akan dibuktikan bahwa sistem positif (1.1) adalah reachable positif. Misalkan sistem (1.1) adalah positif, solusi dari (1.1) adalah sebagai berikut:

$$
\begin{aligned}
\mathbf{x}(k) & =A^{k} \mathbf{x}(0)+\sum_{j=0}^{k-1} A^{k-j-1} B \mathbf{u}(j) \\
& =\left[\begin{array}{llll}
B & A B & \cdots & A^{k-1} B
\end{array}\right]\left(\begin{array}{c}
\mathbf{u}(k-1) \\
\mathbf{u}(k-2) \\
\vdots \\
\mathbf{u}(0)
\end{array}\right)
\end{aligned}
$$

untuk setiap $\mathbf{u}(j) \in \mathbb{R}_{+}^{m}, j=0,1, \cdots, k-1$. Pilih $q=k$, matriks $W$ memuat $n$ kolom monomial bebas linier akibatnya $\mathbf{x}_{f} \in \mathbb{R}_{+}^{n}$ dapat dicapai dalam $k$ langkah. Oleh sebab itu $\mathbf{x}(k)=\mathbf{x}_{f}$.

$(\Rightarrow)$ Misalkan sistem positif (1.1) adalah reachable positif. Akan dibuktikan bahwa matriks $W$ memuat $n$ kolom monomial bebas linier. Sistem (1.1) yang terbentuk adalah reachable positif. Berdasarkan Teorema (2.5) maka $\operatorname{rank}(W)=n$. Tetapi 
karena sistem (1.1) adalah positif, menyebabkan $n$ kolom dari $W$ dapat direduksi menjadi $n$ kolom monomial bebas linier.

Teorema 2.11. [6] Sistem positif (1.1) adalah unreachable positif jika matriks $B$ tidak memiliki kolom-kolom monomial bebas linier.

Bukti. Misalkan $B$ tidak memiliki kolom-kolom monomial bebas linier. Matriks $W$ yang diperoleh tidak memuat $n$ kolom monomial bebas linier untuk setiap $A$. Sehingga sistem (1.1) adalah unreachable positif.

Sebagai suatu ilustrasi, perhatikan contoh berikut :

Contoh 2.12. Perhatikan sistem positif berikut :

$$
\mathbf{x}(i+1)=\left[\begin{array}{llll}
0 & 3 & 0 & 0 \\
4 & 0 & 0 & 0 \\
0 & 0 & 0 & 1 \\
0 & 0 & 1 & 1
\end{array}\right] \mathbf{x}(i)+\left[\begin{array}{ll}
1 & 0 \\
0 & 0 \\
0 & 2 \\
0 & 0
\end{array}\right] \mathbf{u}(i)
$$

Dengan menggunakan Teorema 2.10 diperoleh :

$$
\begin{aligned}
W & =\left[\begin{array}{lllllll}
B & A B & A^{2} & B & A^{3} & B
\end{array}\right] \\
& =\left[\begin{array}{llllllll}
1 & 0 & 0 & 0 & 12 & 0 & 0 & 0 \\
0 & 0 & 4 & 0 & 0 & 0 & 48 & 0 \\
0 & 2 & 0 & 0 & 0 & 2 & 0 & 2 \\
0 & 0 & 0 & 2 & 0 & 2 & 0 & 4
\end{array}\right]
\end{aligned}
$$

Matriks $W$ pada Persamaan (2.8) memiliki 6 kolom monomial, akan tetapi matriks $W$ tersebut hanya memiliki 4 kolom monomial bebas linier maka sistem positif (2.7) yang terbentuk adalah reachable positif.

Contoh 2.13. Selanjutnya perhatikan pula sistem :

$$
\mathbf{x}(i+1)=\left[\begin{array}{lll}
2 & 2 & 1 \\
1 & 3 & 1 \\
1 & 2 & 2
\end{array}\right] \mathbf{x}(i)+\left[\begin{array}{ll}
0 & 1 \\
1 & 1 \\
0 & 1
\end{array}\right] \mathbf{u}(i)
$$

Matriks $W$ untuk sistem (2.9) adalah :

$$
\begin{aligned}
& W=\left[\begin{array}{lll}
B & A B & A^{2} B
\end{array}\right] \\
& =\left[\begin{array}{llllll}
0 & 1 & 2 & 5 & 12 & 25 \\
1 & 1 & 3 & 5 & 13 & 25 \\
0 & 1 & 2 & 5 & 12 & 25
\end{array}\right]
\end{aligned}
$$

Matriks $W$ pada sistem positif (2.9) hanya memiliki 1 kolom monomial bebas linier, maka sistem (2.9) yang terbentuk adalah unreachable positif.

Contoh 2.14. Perhatikan juga sistem berikut :

$$
\mathbf{x}(i+1)=\left[\begin{array}{lll}
1 & 0 & 0 \\
0 & 2 & 0 \\
0 & 0 & 1
\end{array}\right] \mathbf{x}(i)+\left[\begin{array}{ll}
1 & 1 \\
1 & 1 \\
1 & 2
\end{array}\right] \mathbf{u}(i)
$$


Berdasarkan Teorema 2.11, sistem (2.11) adalah unreachable positif. Akan tetapi, perhatikan bahwa :

$$
\begin{aligned}
W & =\left[\begin{array}{lllll}
B & A & B & A^{2} & B
\end{array}\right] \\
& =\left[\begin{array}{llllll}
1 & 1 & 1 & 1 & 1 & 1 \\
1 & 1 & 2 & 2 & 4 & 4 \\
1 & 2 & 1 & 2 & 1 & 2
\end{array}\right]
\end{aligned}
$$

Rank $(W)=3$ maka sistem (2.11) adalah reachable.

Misalkan $\mathbf{x}_{f}=\left(\begin{array}{l}1 \\ 1 \\ 1\end{array}\right)$, diperoleh $\overline{\mathbf{u}}(k)$ sebagai berikut :

$$
\begin{aligned}
& \overline{\mathbf{u}}(k)=W^{T}\left(W W^{T}\right)^{-1}\left(\mathbf{x}_{f}\right) \\
& =\left[\begin{array}{lll}
1 & 1 & 1 \\
1 & 1 & 2 \\
1 & 2 & 1 \\
1 & 2 & 2 \\
1 & 4 & 1 \\
1 & 4 & 2
\end{array}\right]\left(\left[\begin{array}{llllll}
1 & 1 & 1 & 1 & 1 & 1 \\
1 & 1 & 2 & 2 & 4 & 4 \\
1 & 2 & 1 & 2 & 1 & 2
\end{array}\right]\left[\begin{array}{lll}
1 & 1 & 1 \\
1 & 1 & 2 \\
1 & 2 & 1 \\
1 & 2 & 2 \\
1 & 4 & 1 \\
1 & 4 & 2
\end{array}\right]\right)^{-1}\left[\begin{array}{l}
1 \\
1 \\
1
\end{array}\right] \\
& =\left[\begin{array}{c}
0.5238 \\
0.1905 \\
0.3810 \\
0.0476 \\
0.0952 \\
-0.2381
\end{array}\right]
\end{aligned}
$$

Berdasarkan persamaan (2.13) maka diperoleh barisan input $\mathbf{u}(0)=\left(\begin{array}{c}0.0952 \\ -0.2381\end{array}\right)$, $\mathbf{u}(1)=\left(\begin{array}{l}0.3810 \\ 0.0476\end{array}\right)$, dan $\mathbf{u}(2)=\left(\begin{array}{l}0.5238 \\ 0.1905\end{array}\right)$. Selanjutnya akan ditentukan banyak langkah sistem (2.11) reachable dengan menggunakan solusi pada persamaan (1.2)

a. Langkah ke 1

$$
\begin{aligned}
\mathbf{x}(1) & =A^{1} \mathbf{x}(0)+\sum_{k=0}^{0} A^{i-k-1} B \mathbf{u}(k) \\
& =B \mathbf{u}(0) \\
& =\left[\begin{array}{ll}
1 & 1 \\
1 & 1 \\
1 & 2
\end{array}\right]\left[\begin{array}{c}
0.0952 \\
-0.2381
\end{array}\right] \\
& =\left[\begin{array}{l}
-0.1429 \\
-0.1429 \\
-0.3810
\end{array}\right]
\end{aligned}
$$


b. Langkah ke 2

$$
\begin{aligned}
\mathbf{x}(2) & =A^{2} \mathbf{x}(0)+\sum_{k=0}^{1} A^{i-k-1} B \mathbf{u}(k) \\
& =A B \mathbf{u}(0)+B \mathbf{u}(1) \\
& =\left[\begin{array}{ll}
1 & 1 \\
2 & 2 \\
1 & 2
\end{array}\right]\left[\begin{array}{c}
0.0952 \\
-0.2381
\end{array}\right]+\left[\begin{array}{ll}
1 & 1 \\
1 & 1 \\
1 & 2
\end{array}\right]\left[\begin{array}{l}
0.3810 \\
0.0476
\end{array}\right] \\
& =\left[\begin{array}{l}
0.2857 \\
0.1429 \\
0.0952
\end{array}\right]
\end{aligned}
$$

c. Langkah ke 3

$$
\begin{aligned}
\mathbf{x}(3) & =A^{3} \mathbf{x}(0)+\sum_{k=0}^{2} A^{i-k-1} B \mathbf{u}(k) \\
& =A^{2} B \mathbf{u}(0)+A B \mathbf{u}(1)+B \mathbf{u}(2) \\
& =\left[\begin{array}{ll}
1 & 1 \\
4 & 4 \\
1 & 2
\end{array}\right]\left[\begin{array}{c}
0.0952 \\
-0.2381
\end{array}\right]+\left[\begin{array}{ll}
1 & 1 \\
2 & 2 \\
1 & 2
\end{array}\right]\left[\begin{array}{l}
0.3810 \\
0.0476
\end{array}\right] \\
& +\left[\begin{array}{ll}
1 & 1 \\
1 & 1 \\
1 & 2
\end{array}\right]\left[\begin{array}{c}
0.5238 \\
0.1905
\end{array}\right] \\
& =\left[\begin{array}{l}
1 \\
1 \\
1
\end{array}\right]
\end{aligned}
$$

Sistem (2.11) adalah reachable dalam 3 langkah, akan tetapi sistem (2.11) bukanlah reachable positif karena $\overline{\mathbf{u}}(k) \notin \mathbb{R}_{+}^{6}$ pada Persamaan (2.13) .

\section{Kesimpulan}

Kesimpulan dari kajian ini adalah

(1) Sistem linier diskrit positif adalah reachable positif jika dan hanya jika matriks reachability $W$ memuat $n$ kolom monomial bebas linier.

(2) Sistem linier diskrit positif adalah unreachable positif jika matriks $B$ tidak memiliki kolom monomial bebas linier.

\section{Ucapan Terima kasih}

Penulis mengucapkan terima kasih kepada bapak Dr. Mahdhivan Syafwan, ibu Dr. Susila Bahri, ibu Dr. Maiyastri selaku dosen penguji yang telah memberikan masukan dan saran sehingga makalah ini dapat diselesaikan dengan baik. 
Reachability Positif dari Sistem Diskrit Linier Positif 53

\section{Daftar Pustaka}

[1] Anton, H dan Rorres, C. 2005. Aljabar Linier Elementer; Edisi ke-8 . Erlangga, Jakarta

[2] Astolfi, A. 2006. Systems and Control Theory An Introduction. http://www3.imperial.ac.uk, diunduh Mei 2018

[3] Blanchini, F. 2006. Systems and Control Theory. https://users.dimi.uniud.it, diunduh pada Maret 2018

[4] Elaydi, S. 1999 . An Introduction to Difference Equations. Springer Verlag, London

[5] Kaczorek, T. 2002. Positive 1D and 2D Systems. Springer Verlag. London

[6] Kaczorek, T. 2007. New Reachability and Observability Tests for Positive Linear Discrete-Time Systems. Bull. Acad. Pol. Techn. Sci. 55(1): 19-21

[7] Kaczorek, T. 2010. Decomposition of The Pairs (A,B) and (A,C) of Positive Discrete-Time Linear Systems. Arc. Con. Sci. 20(3): 341-361 